DOI: $10.5007 / 2175-7917.2010 v 15 n 1 p 327$

\title{
CORPOS QUE SE ABREM PARA DAR À LUZ
}

\author{
Vanessa Daniele de Moraes \\ Mestranda em Literatura - UFSC
}

\section{RESUMO}

Este artigo propõe pensar questões pertinentes à teoria de Jean-Luc Nancy envolvendo dois contos de Clarice Lispector, dois poemas (um de Manuel Bandeira, outro de Cecília Meireles) e um filme de Alain Resnais. O que se pretende articular em todos os casos são questões como: o sentido, o corpo, a ausência, o toque, a movência do erotismo - buscando nas personagens femininas traços que recusam o corpo como uma verdade absoluta ou como fechamento de sentido, uma vez que as personagens referidas ora se comportam como santas, ora como putas. A partir do texto Noli me tangere, de Jean-Luc Nancy, baseado num episódio bíblico, percebemos que o contato entre Jesus ressuscitado e Maria Madalena não acontece, sendo esta cena o motriz para construirmos uma reflexão acerca do corpus escolhido.

\section{PALAVRAS-CHAVE:}

Corpo; Sentido; Erotismo.

\begin{abstract}
:
This article purposes a consideration on themes relevant to Jean-Luc Nancy's theory, by means of two short-stories by Clarice Lispector, two poems - one by Manuel Bandeira and one by Cecília Meireles - and one movie by Alain Resnais. Concerning all these examples, the aim is to deal with issues related to meaning, body, absence, touch and the eroticism movement - and to investigate traces of the body denial as an absolute truth or as a closure of meaning in the female characters, since they sometimes behave themselves as saints, sometimes as whores. In Noli me tangere, an essay by Jean-Luc Nancy based on a Biblical episode, we become aware that the contact between resuscitated Jesus and Maria Magdalena does not actually happen - and this is a motive scene for composing a consideration on the chosen corpus.
\end{abstract}

\section{KEYWORDS:}

Body; Sense; Eroticism. 
“... no hay ninguna relación sin eros. Pero tampoco hay eros sin agape, es decir, sin ese amor imposible que el judeo-cristianismo cree poder presuponer como naturaleza de Dios y como mandamiento universal." (Jean-Luc Nancy, in El “hay” de la relación sexual)

$\mathrm{Na}$ ânsia de uma discussão sobre o corpo que se abre e prolifera sentidos múltiplos, o presente texto "pari" especialmente a teoria de Jean-Luc Nancy para elencar narrativas de mulheres que possuem uma vida dúbia: ora santas, ora prostitutas. O corpo que se dá por amor, por dinheiro, paixão, erotismo. Partindo do corpo desvendamos a alma: "El cuerpo expresa el espíritu, es decir, lo hace brotar hacia afuera, le saca el jugo, lo hace sudar, le saca chispas y arroja todo en el espacio. Un cuerpo es una deflagración."1 Assim, o corpo deflagra, mas também nos escapa, ele é estranho a nós mesmos: "Desde mi cuerpo yo tengo mi cuerpo como extraño para mí, expropriado"2 Nessa perspectiva, significamos o corpo no seu mover-se, na intempestividade. O corpo é aquele que abre espectros de sentidos; que nos permite aproximar distanciando.

O livro Noli me tangere, de Nancy, traz possibilidades de leitura a respeito de Maria Madalena, figura bíblica que se enquadra no perfil das mulheres que irei traçar neste ensaio. Mas antes disso, devo pontuar o modo como Nancy compreende as parábolas, que é um tipo de texto comum no Novo Testamento. Segundo ele, as parábolas devem ter sentido próprio em sua forma figurada, e por isso mesmo, deveria abrir os olhos "de aquellos que "viendo no ven, y oyendo no oyen ni entienden"” 3 . No entanto, Nancy nega que esses textos esclareçam, baseando-se no capítulo bíblico do livro de Mateus 14, onde o discípulo afirma, grosso modo, que aos que tem se dará e sobrará, e aos que não tem lhes tirarão o pouco que ainda lhe restam. Daí que Nancy postula: "El objetivo de la parábola es por tanto, en primer lugar, mantener en su ceguera al que no ve. No procede de una pedagogía de la figuración (de la alegoría, de la ilustración), sino, muy al contrario, de un rechazo o una negación de pedagogía"4. A verdade (ou a vista), então, estaria reservada aos eleitos, que seriam sempre um pequeno

\footnotetext{
${ }^{1}$ NANCY, Jean-Luc. 58 indicios sobre el cuerpo. Traducido por Daniel Alvaro. Buenos Aires: Ediciones La Cebra, 2007, p. 27 (fragmento 44).

${ }^{2}$ NANCY, Jean-Luc. Corpus. Traducción de Patricio Bulnes. Madrid: Arena Libros, p.18.

${ }^{3}$ Nancy citando Mateus, 13.

${ }^{4}$ NANCY, Jean-Luc. Noli me tangere. Ensayo sobre el levantamiento del cuerpo. Traducción de María Tabuyo y Augustín López. Madrid: Editorial Trotta, 2006, p. 13.
} 
grupo que conseguem "enxergar" aquilo que é transmitido através da parábola: "No hay varios grados de figuración o de literalidad del sentido; hay una sola 'imagen', y frente a ella una visión o una ceguera"5. A parábola, portanto, está na relação da imagem com a vista. Nancy se fundamenta na tese de que

[...] entre la imagen y la vista no hay imitación, hay participación y penetración. Hay participación de la vista en lo visible, y de lo visible a su vez en lo invisible que no es otra cosa que la vista misma. [...] A partir de ahí, la parábola está lejos de dejarse reducir a la fórmula de una alegoría. Participa del don de la vista y ese "más" asegurado a quienes ya la tienen. ${ }^{6}$

Ao contrário das alegorias, as parábolas são tautológicas, se enunciam em si mesmas, e, além disso, seu significado só é encontrado por aqueles que possuem um "ouvido aberto" para a mensagem - por isso o filósofo francês ironiza, vendo aí a necessidade de um autor (de parábolas) ter de criar seus próprios leitores.

Essa breve aclaração da parábola toma consistência quando Nancy fundamenta o episódio do evangelho de João a respeito da ressurreição de Jesus e a quê ele se propõe: "En esta escena, él habla, interpela y se va. Habla para decir que no está allí donde se cree que está, que está en otra parte, estando sin embargo muy presente: aquí, pero no aquí. Al otro le incumbe comprender. Al otro, ver y oír.,"7 E o que notoriamente chama a atenção neste episódio conhecido como "Noli me tangere" é justamente o fato da proibição do contato com Jesus ressuscitado, como se houvesse aí uma advertência ante um perigo. $\mathrm{Na}$ descrição, quando Jesus ressuscitado se aproxima de Maria Madalena no sepulcro, ela não o reconhece (pensa ser o jardineiro). Maria Madalena quer lhe perguntar onde está o corpo de Cristo, mas quando ele a chama pelo nome é que ela o reconhece. E então Jesus pede que ela não lhe toque.

Sabemos que no cristianismo, sobretudo na religião católica, o contato se faz presente a partir da comunhão do corpo de Cristo, nas saudações de paz, e por isso mesmo o Noli me tangere 'foge à regra' do toque (que marca presença, sensibilidade...). Assim, é preciso compreender, com Nancy, o corpo enquanto presença e materialidade ${ }^{8}$. Como em nenhum outro momento dos evangelhos, nessa passagem Cristo nega o ato de

\footnotetext{
${ }^{5}$ NANCY, Jean-Luc. Noli me tangere. Ensayo sobre el levantamiento del cuerpo. op. cit. p. 15.

${ }^{6}$ NANCY, Jean-Luc. Noli me tangere. Ensayo sobre el levantamiento del cuerpo. op. cit.p. 16.

${ }^{7}$ NANCY, Jean-Luc. Noli me tangere. Ensayo sobre el levantamiento del cuerpo. op. cit. p. 21.

${ }^{8}$ Importante ressaltar que para Nancy corpo e pensamento devem ser concebidos enquanto união. $\mathrm{O}$ pensamento também é materialidade. No livro El peso de un pensamiento Nancy dá ênfase para a raiz das palavras "pensar" e "pesar", destacando que as duas, originalmente, queriam dizer medida. Mas como pesar o pensamento? Como medi-lo? Para o autor, não há como pensar em mundo sem considerar esta união.
} 
tocar seu corpo ressuscitado, o que permite pensar que a concepção de eternidade só seja possível a partir da imaterialidade, daquilo que foge ao sensorial:

Su ser y su verdad de resucitado están en esa sustracción, en esa retirada que es lo único que da la medida del toque del que se debe tratar: no tocando ese cuerpo, tocar su eternidad. No llegando al contacto de su presencia manifiesta, acceder a su presencia real, que consiste en su partida. ${ }^{9}$

Se a afirmação de Cristo para a ceia eucarística é: "Este é o meu corpo", sendo este um corpo que se refere à verdade; do ponto de vista pagão podemos pensar a mensagem do "Não queira me tocar" (noli me tangere) como a exclusão do corpo, a exclusão da verdade. O fim agora se torna uma abertura, ou seja, a desconstrução do cristianismo é uma desmontagem para poder abrir o sentido. O Noli me tangere é a representação de uma cena em que o que está presente é irrepresentável, que aproxima e que afasta, que abre o cristianismo para sua própria desconstrução.

Evidentemente, o ponto crucial está no fato de que Maria Madalena vai anunciar que o sentido único se foi, a verdade se dá desaparecendo, e Cristo agora é uma presença que sobrevém na ausência. Por sua vez, o toque é impossível - "em se dando, não se dá”. E o sentido não está ali, mas deixa uma evidência; ele não é algo acabado, mas acontece a cada momento, está na passagem - como na passagem da morte para a ressurreição.

Jesus e Maria Madalena se tocam no intocável. "Não me retenha" - é uma das interpretações do Noli me tangere. O que se pretende aqui é pensar Maria Madalena como um evento que introduz, no âmago da verdade, a impossibilidade de se tocar essa verdade. "María Madalena, sea cual sea su nombre, y su ciudad, es la pecadora, la mujer entregada a la carne para el placer de los hombres a cambio de unas monedas." ${ }^{10}$ E é através de Maria Madalena, puta e escolhida por Deus, digamos assim, que o sentido vai se constituindo e a verdade vai se destituindo. Seu corpo é pura sensação, é abertura contrariamente ao corpo de Maria, mãe de Jesus. Em sua vida, Maria Madalena abre sentidos através do contato, do toque, da relação sexual, contrapondo-se à Virgem Maria, que concebe Jesus sem o contato humano. O corpo da virgem é fechamento (não-corpo). O corpo de Maria Madalena é justamente o contrário: é abertura de sentidos, sensações.

\footnotetext{
${ }^{9} \mathrm{NANCY}$, Jean-Luc. Noli me tangere. Ensayo sobre el levantamiento del cuerpo. Op. Cit. p. 27. ${ }^{10}$ NANCY, Jean-Luc. Noli me tangere. Ensayo sobre el levantamiento del cuerpo. Op. Cit. p. 91.
} 


\section{MARIA EGIPCÍACA - A ENTREGA DO CORPO E DA ALMA}

Tal qual Maria Madalena, temos Santa Maria Egipcíaca, mulher que teve sua história transcrita para o teatro por Cecília Meireles e também virou poema de Manoel Bandeira. Como a primeira, o corpo da segunda também é abertura, se o tomarmos no sentido amplo, isto é, um lugar do desejo, intruso em qualquer espaço pensado enquanto finitude. Maria Egipcíaca, nascida no Egito, foi aos doze anos a Alexandria e se prostituiu durante dezessete anos. Quando resolveu fazer uma viagem a Jerusalém para adorar a cruz, pediu para ir de navio com os marinheiros. Não tendo dinheiro para pagar a viagem, pagou com o próprio corpo. Lá chegando, sentiu-se suja e, ao ver uma imagem da Virgem Maria rogou-lhe perdão. Solitária, fez penitência no deserto por quarenta e sete anos, mantendo seu voto de castidade. Em seus últimos anos de vida, no entanto, encontrou um velho e pediu que este lhe trouxesse uma hóstia consagrada (corpo de Cristo) para que ela comungasse, ao que ele fez. No ano seguinte, na época de Páscoa, o velho voltou ao deserto para repetir o gesto, e encontrou Maria Egipcíaca morta. Ao lado de sua cabeça, um bilhete dava a entender que ela havia morrido depois de ter recebido o corpo de Cristo, naquela última vez em que ele a visitara. Segundo a tradição, o velho não tinha forças para enterrar a mulher, e vendo um leão se aproximar, disse-lhe: "Esta santa me pediu que a enterrasse, e eu não posso cavar a terra, arranha-a tanto que possamos enterrar o corpo santo." ${ }^{11}$. Assim o leão o fez e depois de ter o corpo enterrado o velho voltou ao seu mosteiro glorificando a Deus.

Essa lenda, contada de maneira poética por Cecília Meireles, nos leva a pensar metaforicamente que a santa, após tomar o corpo de Cristo, entregou-lhe a alma. ${ }^{12} \mathrm{Com}$ a abstinência, a santa havia recalcado seu corpo, negando-o a si mesma. Georges Bataille, no prefácio d'O Erotismo nos atenta para o recalcamento do corpo:

O espírito humano está exposto às mais surpreendentes injunções. Constantemente ele teme a si mesmo. Seus movimentos eróticos o apavoram. A santa afasta-se com terror do sensual: ela ignora a unidade de suas paixões

\footnotetext{
${ }^{11}$ MEIRELES, Cecília. Oratório de Santa Maria Egipcíaca. Rio de Janeiro: Nova Fronteira, 1996, p. 13.

${ }^{12}$ No pequeno texto intitulado Extensión del alma, Nancy trata da união da alma e do corpo tomando como ponto norteador a carta de Descartes à Elisabeth no ano de 1643. E mais adiante, comentando esta carta, Nancy conclui: "El cuerpo se conoce en cuanto que es alma, o que está íntimamente unido a ella. Pero el alma se conoce así como extensión, no a través del cuerpo, sino según la extensión del cuerpo.'In.: NANCY, Jean-Luc. Extensión del alma. Trad. Daniel Alvaro. Buenos Aires: La Cebra, 2007. p. $40-41$.
} 
inconfessáveis deste último com as suas. Entretanto, é possível procurar a coesão do espírito humano, cujas possibilidades vão da santa ao sensual. ${ }^{13}$

Manuel Bandeira preferiu abordar no poema apenas a questão do interdito, não frisou a penitência como fez Meireles, mas deu atenção à "abertura do corpo", como entrega da santidade. Os católicos mais fervorosos poderiam censurá-lo, tachá-lo de profano, mas o fato é que seu linguajar escrachado nos permite novas possibilidades de leitura ${ }^{14}$. Eis o poema:

\section{Balada de Santa Maria Egipcíaca ${ }^{15}$}

Santa Maria Egipcíaca seguia

Em peregrinação à terra do Senhor.

Caía o crepúsculo, e era como um triste sorriso de mártir.

Santa Maria Egipcíaca chegou

À beira de um grande rio.

Era tão longe a outra margem!

E estava junto à ribanceira,

Num barco,

Um homem de olhar duro.

Santa Maria Egipcíaca rogou:

- Levai-me à outra parte do rio.

Não tenho dinheiro. O Senhor te abençoe.

O homem duro fitou-a sem dó.

Caía o crepúsculo, e era como um triste sorriso de mártir.

- Não tenho dinheiro. O senhor te abençoe.

Leva-me à outra parte.

O homem duro escarneceu: - Não tens dinheiro,

Mulher, mas tens teu corpo. Dá-me teu corpo, e vou levar-te.

E fez um gesto. E a santa sorriu,

$\mathrm{Na}$ graça divina, ao gesto que ele fez.

Santa Maria Egipcíaca despiu

O manto, e entregou ao barqueiro

\footnotetext{
${ }^{13}$ BATAILLE, Georges. O erotismo. Trad. Antonio Carlos Viana. Porto Alegre: L\&PM, 1987, p. 7.

${ }^{14}$ Serão discutidas após o poema.

${ }^{15}$ BANDEIRA, Manuel. Estrela da Vida Inteira. 34 ed. Rio de Janeiro: José Olympio Editora, 1993, p. 106.
} 
A santidade da sua nudez.

O livro já citado de Bataille vai atentar para a questão da violação de tabus para entrar no cerne de seu tema, que é o erotismo. O autor ironiza e até viola conceitos preestabelecidos socialmente ao afirmar: "Toda a concretização do erotismo tem por fim atingir o mais íntimo do ser, no ponto em que o coração nos falta." ${ }^{\prime 6}$ É assim que Bataille introduz a idéia da violência, da morte, para que haja erotismo: "Essencialmente, o domínio do erotismo é o domínio da violência, o domínio da violação. (...) O mais violento para nós é a morte que, precisamente, nos arranca da obstinação que temos de ver durar o ser descontínuo que nós somos." ${ }^{17}$ Nessa perspectiva ele cita Sade, que diz que "Não há melhor meio para se familiarizar com a morte do que associá-la a uma idéia libertina."18 Bataille e Nancy convergem neste ponto: compreendem a morte como abertura de sentido, como continuidade; sendo que a descontinuidade do ser tem a ver com a reprodução, com o fechamento. Assim, Nancy chama a atenção para a morte como um evento que abre a relação, como por exemplo, a putrefação sempre vivificante para novas germinações. Ele esclarece: "Sin la muerte no habría más que contacto, contigüidad y contagio, propagación cancerosa de la vida que, por conseguiente, no sería ya la vida; o bien sería sólo la vida, no la existencia, no sería al mismo tiempo la anastasis. La muerte abre la relación es decir, el compartir la partida. Cada uno viene y parte sin fin, incesantemente." 19

No caso do poema de Bandeira, o artifício libertino é utilizado entrecruzando idéia de santidade e nudez. Ou melhor: "da santidade da nudez". E essa idéia esbarra também no pensamento de Bataille:

A nudez se opõe ao estado fechado, isto é, ao estado de existência descontínua. É um estado de comunicação que revela a busca de uma continuidade possível do ser para além do voltar-se a si mesmo. Os corpos se abrem para a continuidade através desses canais secretos que nos dão o sentimento da obscenidade. A obscenidade significa a desordem que perturba um estado dos corpos que estão conforme à posse de si, à posse da individualidade durável e afirmada. Há, ao contrário, desapossamento no jogo dos órgãos que se derramam no renovar da fusão, semelhante ao vaivém das ondas que se penetram e se perdem uma na outra. Esse desapossamento é tão completo que no estado de nudez, que o anuncia, e que é seu emblema, a maior parte dos seres humanos se esconde, mais ainda se a ação erótica, que acaba de desapossá-los, acompanha a nudez. O desnudar-se, visto nas

\footnotetext{
${ }^{16}$ BATAILLE, Georges. O erotismo. Op. Cit. p. 16-17.

${ }^{17}$ BATAILLE, Georges. O erotismo. Op. Cit. p. 16.

${ }^{18}$ BATAILLE apud SADE. O erotismo. Op. Cit. p. 12.

${ }^{19}$ NANCY, Jean-Luc. Noli me tangere. Ensayo sobre el levantamiento del cuerpo Op. Cit. p. 72.
} 
civilizações onde isso tem um sentido pleno, é, quando não um simulacro, pelo menos uma equivalência sem gravidade da imolação. ${ }^{20}$

A imolação de que Bataille se refere estabelece uma relação entre o ato de amor e o sacrifício, no período da Antiguidade. Tal relação implicava na figura masculina como um sacrificador, e a figura feminina como vítima, durante a consumação do ato sexual. Dessa forma, o ato constituía uma continuidade destrutiva.

Os últimos versos do poema de Bandeira: "Santa Maria Egipcíaca despiu / O manto, e entregou ao barqueiro / A santidade da sua nudez." trazem o que, na contramão do cristianismo, poderia ser visto como um erotismo sagrado, dum outro ponto de vista religioso (em que o sentimento do sagrado domina a vergonha). O sagrado, em síntese, é tudo aquilo que é objeto de um interdito, mas ele abre-se a transgressões ilimitadas. Bataille nos lembra dos templos da Índia, cheios de figuras eróticas talhadas na pedra, “onde o erotismo se dá pelo que ele é fundamentalmente: ele é divino. Inúmeros templos da Índia lembram-nos solenemente a obscenidade no fundo de nosso coração" 21 Mas a santa-prostituta de Cecília Meireles, diferentemente da descrição de Bandeira, carrega o jugo da vergonha, da penitência, da imoralidade. A santa de Bandeira, por sua vez, sorri para o barqueiro em resposta ao gesto que ele fez ao pedir o corpo como pagamento. A entrega do corpo de Maria Egipcíaca, vista aqui como sacrifício, faz conexão com a afirmação de Bataille: "Hoje o sacrifício sai do campo de nossa experiência: devemos substituir a prática pela imaginação."22. Da mesma forma, num período posterior, a entrega do corpo ao celibato corresponderia ao sacrifício deste corpo, dum corpo que se fecha e não abre - definitivamente. Maria Egipcíaca encerra sua vida ao comer um corpo alheio ao seu. Mas o seu corpo mesmo lhe é desconhecido, é fora dela, está fora. É aí que podemos compreender o corpo como um órgão estranho a nós mesmos, inventado, excrito, para dizer com Nancy:

La angustia, el deseo de ver, de tocar y comer el cuerpo de Dios, de ser ese cuerpo y de no ser sino eso constituyen el principio de (sin) razón de Occidente. Por esto, el cuerpo, jamás tuvo ahí lugar, y menos que nunca cuando ahí se lo nombra y se lo convoca. El cuerpo para nosotros es siempre sacrificado: hostia.

Si hoc est enim corpus meum dice algo, es fuera de habla, no es dicho, está excrito - a cuerpo descubierto. ${ }^{23}$

\footnotetext{
${ }^{20}$ BATAILLE, Georges. O erotismo. Op. Cit. p. 17.

${ }^{21}$ BATAILLE, Georges. O erotismo. Op. Cit. p. 126.

${ }^{22}$ BATAILLE, Georges. O erotismo. Op. Cit. p. 85.

${ }^{23}$ NANCY, Jean-Luc. Corpus. Op. Cit. p. 9.
} 
O corpo que se desnuda, do qual se escreve, e, sobretudo, que se excreve é, ele mesmo, a própria escritura, uma vez que a escritura toca o corpo, por essência, e o corpo dá lugar à existência. Dessa forma, o corpo funda um lugar: "Un cuerpo es el lugar que abre, que separa, que espacia falo y céfalo: dándoles lugar a hacer acontecimientos (gozar, sufrir, pensar, nacer, morir, hacer sexo, reír, estornudar, temblar, llorar, olvidar...) ${ }^{24}$. Sendo a escritura o lugar - por excelência - do toque, ela é essencialmente exposição, excritura; e nosso corpo nos é excrito, nos é exposto. Até que ponto nosso corpo é nosso, até que ponto ele nos é alheio? Maria Egipcíaca na peregrinação: até que ponto seu corpo não é estranho a si própria? "Ex-istencia: los cuerpos son el existir, el acto mismo de la ex-istencia, el ser." 25

\section{CLARICE E O EROTISMO}

Numa tentativa de justificar os motivos da ousadia que levou Clarice Lispector a escrever seu único livro com dosagens de erotismo, a escritora faz um prólogo intitulado "Explicação" para A via crucis do corpo. Nesse prólogo, ressalta que escreveu o livro por encomenda, e que apesar dos riscos, tratava-se de um desafio. Chama-nos a atenção quando afirma: "Todas as histórias deste livro são contundentes. E quem mais sofreu fui eu mesma. Fiquei chocada com a realidade. Se há indecências nas histórias a culpa não é minha. Inútil dizer que não aconteceram comigo, com minha família e com meus amigos. Como é que sei? Sabendo. Artistas sabem de coisas" ${ }^{\text {26 }}$. Essa afirmação vem negar aquela noção do senso comum de que artista já deve ter sua arte premeditada ou que as criações devem ser acabadas. A arte deve ser pensada como movimento, como busca em torno daquilo que resta ${ }^{27}$. Maurice Blanchot segue pela mesma via: "ser artista é nunca saber que já existe uma arte, nem que já existe um mundo". ${ }^{28}$ A produção de sentido na literatura de Clarice Lispector, sobretudo neste livro, vai se constituindo a partir do momento em que ela confessa estar "chocada com a realidade", quando esta lhe toca e ela já não sabe distinguir o que é literatura, o que é a realidade - ou é tudo uma coisa só, ao que parece. Quando escreve, é o corpo alheio que excreve: "Hace falta,

\footnotetext{
${ }^{24}$ NANCY, Jean-Luc. Corpus, Op. Cit. p. 17.

${ }^{25}$ NANCY, Jean-Luc. Corpus, Op. Cit. p. 18.

${ }^{26}$ LISPECTOR, Clarice. A via crucis do corpo. Rio de Janeiro: Nova Fronteira. p. 7.

27 Ver mais em: NANCY, Jean-Luc. "El vestigio del arte". In.: Horacio Pons. Buenos Aires: Amotorru, 2008, p. 113.

${ }^{28}$ BLANCHOT, Maurice. "O desaparecimento da literatura". In.: Leyla Perrone-Moisés. São Paulo: Martins Fontes. p.294. Las musas. Traducción de O livro por vir. Tradução de
} 
pues, escribir desde ese cuerpo que nosotros tenemos y que tampoco somos: pero donde el ser es excrito. - Cuando escribo, esta mano ajena ya se ha deslizado en mi mano que escribe." 29 Blanchot parece concordar, pois defende que "o que atrai o escritor, o que impulsiona o artista não é diretamente a obra, é a sua busca, o movimento que conduz a ela, a aproximação que torna a obra possível: a arte, a literatura e o que essas duas palavras dissimulam." 30

O livro de Clarice foi escrito pela promessa, pela vontade, por querer ser a história do outro. Houve o desejo, e houve um corpo desconhecido a ela mesma. E apenas quando algo toca Clarice, há produção de sentido, há o assombro, mas também fica a ambigüidade em saber aí quem é tocado, pois o gesto do artista também toca, também fere, também afeta. Mas o sentido, se quisermos entender com Jean-Luc Nancy, é uma presença que se ausenta, é um chegar que escapa. É através do contato que existe o afeto, mas esse contato é feito através do corpo. E a literatura de Clarice também é isso, uma escrita do corpo que se faz com o próprio corpo ${ }^{31}$, com afeto: é ser tocado por e tocar em. É a mão que escreve e ex-creve sentidos. Não tem causa nem origem, ela simplesmente é. Num dos contos, Clarice desabafa: "Pois é. Sei lá se este livro vai acrescentar alguma coisa à minha obra. Minha obra que se dane. Não sei por que as pessoas dão tanta importância à literatura. E quanto ao meu nome? Que se dane, tenho mais em que pensar." 32 E é justamente pela via afetiva que leio a primeira estória deste livro, "Miss Algrave". O conto clariceano narra o episódio de uma moça chamada Ruth, que se conserva virgem e considera tudo um grande pecado - tanto que via o acasalamento dos animais como uma infâmia à moral, e tomava banho uma vez por semana de lingerie para não se ver nua. No seu modo de pensar, sua própria existência tinha um quê de impureza, já que seus pais fizeram sexo para que ela pudesse nascer. $\mathrm{O}$ fato é que certa noite um ser de Saturno entrou pela janela pra lhe amar e ela amou (literalmente). Ruth não viu Ixtlan (esse era o nome dele), mas sentiu-o. A partir daí o

\footnotetext{
${ }^{29}$ NANCY, Jean-Luc. Corpus. Op. Cit. p.19.

${ }^{30}$ BLANCHOT, Maurice. "O desaparecimento da literatura”. In.:

O livro por vir. op. cit. p.291.

${ }^{31}$ Nancy pode elucidar bem essa questão do corpo fazendo(-se) escritura: "Escribir: tocar el extremo. ¿Como entonces tocar el cuerpo, en lugar de significarlo o de hacerlo significar? Uno está tentando de responder con prisa que o bien eso es imposible, que el cuerpo es lo ininscriptible, o bien que se trata de remendar o de amoldar el cuerpo a la misma escritura (bailar, sangrar...). Respuestas sin duda inevitables - sin embargo, rápidas, convenidas, insuficientes: una y otra hablan en el fondo de significar el cuerpo, directa o indirectamente, como ausencia o como presencia. Escribir no es significar. Se ha preguntado: ¿Cómo tocar el cuerpo? Puede que no sea posible responder a este 'como', como si de una pregunta técnica tratara. Pero lo que hay que decir es que eso - tocar el cuerpo, tocarlo, tocar en fin - ocurre todo el tiempo en la escritura.". In: NANCY, Jean-Luc. Corpus. p. 12.

${ }^{32}$ LISPECTOR, Clarice. A via crucis do corpo. Op. Cit. p. 59.
} 
comportamento de Ruth se transforma radicalmente, a "santa" que era, agora se prostitui. A moça que via libertinagem em tudo, torna-se, ela mesma, uma libertina. A vaidade lhe domina. Abandona o emprego de datilógrafa para ficar na rua levando homens ao seu quarto, pois esses lhe pagariam muito bem. "E quando chegasse a lua cheia - tomaria um banho purificador de todos os homens para estar pronta para $\mathrm{o}$ festim com Ixtlan". 33

No plano do incorpóreo ou do invisível, Ixtlan é o ser distinto que veio de Saturno para amar Ruth, mas, segundo a narradora, eles só se entendiam em sânscrito. Essa relação entre eles (sobretudo a sexual) propiciava que Ruth tivesse sensações que outrora não tinha, e de certo modo tinha medo de que isso acabasse. Mas é preciso compreender que a relação só tem seu lugar mediante a distinção, uma vez que os corpos que se distinguem, "lo hacen necesariamente en el doble sentido de que se se separan y de que esta separación permite que uno tenga relación con el outro"34. Já no prólogo d' El hay de la relación sexual Nancy faz uma contestação ao pensamento psicanalítico, em especial ao pensamento lacaniano, pois sua concepção é de que a relação sexual tem sim seu lugar (ao contrário da tese de Lacan). A relação não está dada, mas se dá, ela ocorre, sobrevém. Ela tem lugar na incomensurabilidade:

Lo que tiene lugar como relación no es un puente tendido entre dos individuos, ni la producción de un tercero. Lo que tiene lugar es la inconmensurabilidad de ambos. Es la medida en que son inconmensurables por lo que entran en la relación, o por lo que la relación los atraviesa. ${ }^{35}$

Tal como Noli me tangere, aqui também se trata da reciprocidade do toque. Os sujeitos agora são atravessados pela relação sexual, e simultaneamente pelo gozo. Ruth manifesta a dor do perder, do não reter o gozo, do desejo incessante do mais-além. Só há sujeitos desejantes de si no desejo do outro. A protagonista de Clarice pergunta a Ixtlan como faria sem ele, diante de tanta saudade, e ele responde: "use-se".

Esse desejo-prazer que é sentido por Ruth, no entanto, proporciona demasiado disprazer, pois "el placer no se da sin que toque al sufrimiento, ni la alegría a la angustia: ese tocar mismo tampoco se da, como debe ser, sin separación ni diferenciación. ${ }^{36}$ O gozo, na concepção de Nancy, é o excesso em relação a si; e a dor,

\footnotetext{
${ }^{33}$ LISPECTOR, Clarice. A via crucis do corpo. Op. Cit. p. 22.

${ }^{34}$ NANCY, Jean-Luc. El hay de la relación sexual. Traducción: Cristina de Peretti y Francisco J. Vidarte. Madrid: Editorial Síntesis, 2001. p. 27.

${ }^{35}$ NANCY, Jean-Luc. El hay de la relación sexual. Op. Cit. p. 9

${ }^{36}$ NANCY, Jean-Luc. El hay de la relación sexual. Op. Cit. p. 40.
} 
a falta. Novamente a distinção com Lacan: este último vê a falta como angústia, não como dor. A angústia é sentida quando o objeto de desejo não vem, mas para Nancy, não há objeto, não há coisas, não há posses, não há nada para doar. Reforça-se aí a idéia de que o sentido não existe enquanto algo acabado, ele se dá a cada momento, ele é passagem. No entanto, o sujeito do desejo é insaciável. O corpo é pura sensação, é abertura. No conto, Ruth se relaciona com Ixtlan e não se sente saciada nunca mais. É excesso, como aqui:

El sexo se excede por esencia y, por eso, por esencia de nuevo, se excita. Pues referirse, en el sentido que ha apuntado, es excitarse: pro-ferirse, manar o brotar fuera. Así, el deseo, cuando se apacigua, no por ello se extingue: al acceder a su descarga, se excede de nuevo. ${ }^{37}$

O esgotamento da relação sexual ou a proximidade de seu fim deixa um lamento, um gemido, quase uma súplica. A necessidade do término é o disprazer trazido após o prazer. Além disso, há que lembrarmos a possibilidade de Ruth amar Ixtlan por não haver exigências entre eles, era apenas amor e nada mais, e essa (in)condição nos faz recordar do texto de Nancy a respeito de Maria Madalena, onde o amor de Cristo pela pecadora se dá exatamente por não haver condições/favores para o amor:

Ha sabido que él la amaba porque él no le ha pedido ni le ha propuesto nada. No le ha propuesto pagarle una porción de amor, la ha amado. No la ha amado con un sentimiento de ternura, de compasión o ardor: no le ha pedido nada y al no le pedir nada le estaba haciendo un sitio. Y esto ya era amor. Era amor sin palabras ni movimientos, sólo con un perfume. ${ }^{38}$

De acordo com a tradição cristã, o mundo é objeto de criação divina e nenhuma criatura é sua própria essência, pois tem seu ser em um criador que não tem mais substância que a da relação mesma. Inversamente ao pensamento platônico, que visa reunir o amor dos corpos e o amor das almas, a vertente cristã visa "infinitizações" (do homem e do mundo), opõe-se natureza e graça, onde a natureza corresponde ao apetite insaciável, e a graça, à oferenda inesgotável. Mas Nancy reverte a tradição: o mundo é devir, não é totalizável, é incomensurável. E o corpo é sem essência, é excrescência, é movimento. Em El "hay" de la relación sexual, pontua a relação entre amor e desejo, entre finitude e infinitude:

El amor y el deseo se rigen y se excluyen quizá mutuamente, al representar cada uno a la vez la finición y la infinición del otro, al poder caer cada uno fuera del otro a pesar, no obstante, de que ninguno subsiste en su esencia forcluido del otro. En cada gesto do deseo, tiene que haber amor, y al revés. Pero esto puede tender, en cada caso, hacia el desvanecimiento de uno o de

\footnotetext{
${ }^{37}$ NANCY, Jean-Luc. El hay de la relación sexual. Op. Cit. p. 45.

${ }^{38}$ NANCY, Jean-Luc. Noli me tangere. Op. Cit. p. 94.
} 
otro. El amor y el deseo serían, de este modo, los dos polos de cada relación, de su tener-lugar sin lugar, estando ellos mismos, uno respecto del otro, en una relación sin relación. ${ }^{39}$

Assim é possível pensar no amor de Ruth a partir de seu corpo, que é lugar de desejo... Seu corpo, antes de Ixtlan, era fechamento: não era possível ter contato, ter afeto. Agora toca, compartilha. Um contato os une e os separa

"Via crucis" 40 , outro conto de Clarice Lispector, se pauta numa narrativa bíblica para ilustrar a história do nascimento de um Cristo reinventado. Não se sabe se ele passou pela via crucis, como afirma a narradora, mas a forma em que ela chama a atenção para o conflito de Maria recebe novos contornos interpretativos. Maria das Dores, personagem deste conto, ecoa a tradição cristã em que uma virgem se descobre grávida. Diante da notícia do médico, o assombro. O médico pergunta se Maria não é casada, e ela responde: “- Sou, mas sou virgem, meu marido nunca me tocou. Primeiro porque ele é homem paciente, segundo porque já é meio impotente." ${ }^{\natural 1}$

A gravidez se confirma e os personagens vão traçando caminhos propositalmente semelhantes aos de Jesus, Maria e José - Maria das Dores, por exemplo, começa a chamar seu marido de São José, se preocupam com a data do nascimento do filho (pois estaria prevista para outubro, e não para 25 de dezembro), vão atrás de um estábulo e de roupas análogas às descritas na bíblia. Por fim, não deram ao filho o nome de Jesus para que ele não passasse pela crucificação, então escolheram Emmanuel. Clarice Lispector termina o conto "deixando-o aberto", sendo o fim uma abertura, tal como Nancy sugere. Na última frase temos: "Não se sabe se essa criança teve que passar pela via crucis. Todos passam." ${ }^{42}$ Ao que vemos, a própria mãe desse Cristo é "das Dores", o que não deve ser uma escolha fortuita de Clarice.

Mas o que chama atenção nesse conto é que novamente podemos retomar a questão do toque, ou ainda do não toque - "não queiras me tocar" (Noli me tangere). Aqui, como a Virgem Maria, Maria das Dores foi a personagem que engravidou virgem. O não contato, nesse sentido, é que "daria sentido" à história bíblica.

\footnotetext{
${ }^{39}$ NANCY, Jean-Luc. El hay de la relación sexual. Op. Cit. p. 56.

${ }^{40}$ Ver em: LISPECTOR, Clarice. A via crucis do corpo. Rio de Janeiro: Nova Fronteira, 1984.

${ }^{41}$ LISPECTOR, Clarice. A via crucis do corpo. Op. Cit. p. 33.

${ }^{42}$ LISPECTOR, Clarice. A via crucis do corpo. Op. Cit. p. 38.
} 
A explicação sobre o toque que faz Nancy em Noli me tangere (episódio de Jesus e Maria Madalena) pode fazer sentido se transferida para cá... Ler essa recusa do contato ou da relação sexual como um intenso desejo que só se realiza no inalcançável:

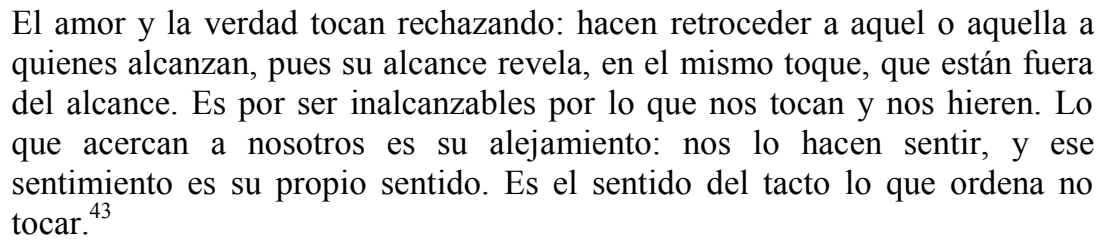

A partida de Jesus como verdade que se vai e não se deixa tocar nos permite pensar também naquilo que afeta por intermédio do distanciamento; na presença que se dá na ausência. Nancy, a respeito de Maria Madalena, afirma: "Ama lo que se te escapa, ama a aquel que se va. Ama que se vaya"44

Atribuir a teoria de Nancy ao Cristo (ou Emmanuel) de Clarice é interessante porque o teórico compreende o sujeito como irrepresentável, uma vez que a representação pressupõe um sujeito constituído, e o sujeito (nessa linha de pensamento) nunca se fecha, se afasta, não se dá como produto acabado, é indistinto. No conto de Clarice não se sabe se a criança passou pela via crucis, por exemplo, e o sentido se dá nessa abertura que a narradora deixa. Aqui há falta, não há acabamento. Em Noli me tangere, como já foi dito, Cristo aparece para Maria Madalena na sua retirada, é partindo que ele se apresenta. O modo incerto como Cristo vai morrer (se é que vai) no conto de Clarice esbarra novamente nessa teoria, onde a morte é a possibilidade última da experiência, é o fracasso, é o que não pode ser pensado nem narrado. Tudo deve ser concebido então em sua incompletude, na pulsação (como o sopro de vida clariceano), pois a arte é inacabada, é processo - não fechamento. A linguagem e a morte correspondem ao excrito, para Nancy. A linguagem é a morte. E dentro da experiência da vida, a morte é o impossível.

\section{O CORPO E A TRANSGRESSÃO}

Outra abordagem que alça os dois extremos da mulher está no filme Medos privados em lugares públicos, do diretor Alain Resnais. Charlotte, uma das

\footnotetext{
${ }^{43}$ NANCY, Jean-Luc. Noli me tangere. p. 59.

${ }^{44}$ NANCY, Jean-Luc. Noli me tangere. p. 60.
} 
personagens, transita entre o profano e o sagrado, entre a interdição do erotismo e sua liberação total. Ela é uma mulher que se ocupa como corretora de imóveis durante o dia, e começa a trabalhar como enfermeira no período da noite. O velho que está sob seus cuidados tem um histórico de maltratar todas as enfermeiras que passam por ele, e com Charlotte não é diferente. $\mathrm{O}$ velho, preso à cama pela doença que o degenera, grita, ofende Charlotte, lhe chama de vadia, cadela, vaca estúpida. Aparentemente essa mulher é forte e resiste às ofensas porque é perseverante aos preceitos religiosos, faz caridade e lê a bíblia com freqüência. Por outro lado, o filme vai desvelando outra face da Charlotte, que entrega fitas de vídeo a Tierry, seu colega da imobiliária, para que ele assista aos programas de sua igreja, e o conteúdo das fitas se tornam contraditórios quando ele assiste a um strip-tease sensual da própria colega. À noite, o comportamento dúbio de Charlotte persiste quando ela surpreende o velho doente com adereços sensuais, danças eróticas e um streap-tease que acaba por enfartá-lo. Já com Tierry, o colega da imobiliária, o interessante é que, a qualquer comentário mais ousado que este lhe fizesse, Charlotte zangava-se, mostrava-se uma mulher pura e inocente, o que se contradizia com suas outras atitudes já referidas aqui.

De acordo com Bataille, as mulheres, em sua atitude passiva, suscitam o desejo masculino: "Elas não são mais desejáveis, mas se propõem ao desejo." ${ }^{45}$. Assim, mesmo a mais casta das mulheres teria potencialidade para a prostituição, uma vez que há nela um cuidado com sua beleza, além de uma excessiva preocupação com os adereços. Bataille é enfático: “...uma mulher considera a si mesma como um objeto que ela, constantemente, propõe à atenção dos homens. Igualmente, se ela se desnuda, revela o objeto do desejo de um homem, um objeto distinto, individualmente proposto à apreciação." ${ }^{46}$ Entretanto, a nudez resiste a todo ornamento feminino, o que negaria a assertiva dos enfeites da mulher como tentativa de oferecimento aos homens, mas a tese se justifica pelo fato de que "a mulher nua está próxima do momento da fusão, que ela anuncia" ${ }^{47}$, sendo o objeto seu próprio corpo, sua nudez.

Se a sedução é a atitude fundamental da mulher, certamente esse oferecimento também pode vir a ser um fingimento de sua negação. Charlotte insere os homens que a rodeiam (o velho, o pai do velho e Tierry) num jogo de oferecimento paralelo ao comportamento recalcado - chega a confundir Tierry, muitas vezes. Pensar a

\footnotetext{
${ }^{45}$ BATAILlE, Georges. O erotismo. Op. Cit. p. 123.

${ }^{46}$ BATAILLE, Georges. O erotismo. Op. Cit. p. 123.

${ }^{47}$ BATAILLE, Georges. O erotismo. Op. Cit. p. 123.
} 
prostituição como um jogo onde a esquivez e o oferecimento são formas de excitar o desejo masculino pode ter certa dose de erotismo, mas Bataille admite que esse jogo se torna perigoso quando a prostituição é uma "questão de sobrevivência" para a mulher:

\begin{abstract}
A prostituição formal é uma proposição onde o fingimento não existe. A prostituição admitiu só os adornos que sublinham o valor erótico do objeto. Um tal adorno em princípio é contrário ao segundo movimento, quando uma mulher foge ao ataque. O jogo é o uso de um adereço que tem o sentido da prostituição: a esquivez, a seguir excita o desejo, ou às vezes o fingimento da esquivez. Em primeiro lugar, a prostituição não é exterior ao jogo. As atitudes femininas formam contrários complementares. A prostituição de algumas alimenta a esquivez de outras, e vice-versa. Mas o jogo é deturpado pela miséria, na medida em que se vê na prostituição uma saída. Neste caso, a prostituição é uma chaga. ${ }^{48}$
\end{abstract}

Segundo Bataille, os presentes recebidos em trocas dos favores sexuais (ornamentos ou somas de dinheiro) acabavam tornando um círculo vicioso, onde os homens ricos reverenciavam as prostitutas com jóias, que iriam servir como objetos de sedução a eles mesmos. Por sua vez, no casamento, a mulher era sim objeto masculino, mas nesse caso, eram desejadas como instrumentos de trabalhos domésticos, e principalmente do trabalho agrícola.

O erotismo, então, emergia somente nas relações fora do casamento, onde não houvesse a possibilidade de um costume produtivo, ao contrário, "a provocação do desejo era excitante: a prostituta podia consumir toda a riqueza e a vida daquele em quem provocava o desejo." 49 No filme de Resnais, a personagem Charlotte provoca demasiadamente o velho ranzinza até tirar-lhe a vida. Charlote transgride e deixa-se extravasar dentro de seus próprios preceitos religiosos. Usa um corpo que muitas vezes desconhece para vingar, para erotizar, e para provar a ela mesma que tem capacidade de seduzir. Charlotte oferta seu corpo em troca de auto-afirmação, de vingança ou de vaidade. Prostitui-se. Transgride.

Mais uma vez Bataille vem contribuir, ao dizer que a transgressão, tempos atrás, podia ter seu caráter sagrado dentro do cristianismo, uma vez que a vida da prostituta era dedicada integralmente à violação do tabu (interdito) da atividade sexual, mas possuía uma coerência institucional, desconhecendo até mesmo a vergonha: "as prostitutas, em contato com o sagrado, em lugares consagrados, tinham um caráter

\footnotetext{
${ }^{48}$ BATAILlE, Georges. O erotismo. Op. Cit. p. 124.

${ }^{49}$ BATAILLE, Georges. O erotismo. Op. Cit. p. 124.
} 
sagrado análogo ao dos sacerdotes." ${ }^{, 50}$ Numa concepção diferente dos tempos atuais, a cortesã era respeitada, não havia motivos para ter pudor já que não estava destinada ao desprezo. O único princípio que ela deveria seguir é o do primeiro contato - que deveria haver medo na hora da entrega e uma reação de fuga era esperada por parte dos homens. A vergonha, por sua vez, era simulada muitas vezes pois o homem não podia ter o sentimento de que a lei estivesse sendo violada nele mesmo, por isso a mulher fingia constrangimento para que o homem desconsiderasse aquele ato como uma violação do interdito.

O que percebemos na trama fílmica é esse constrangimento de Charlotte ao ser cortejada por Tierry, um constrangimento que pode perfeitamente ser fingimento a fim de querer afastar o desejo. Michel Foucault, num texto que homenageia Bataille, nos diz que a sexualidade é a única partilha ainda possível num mundo onde não há mais nada a profanar: "Ora, uma profanação em um mundo que não reconhece mais sentido positivo no sagrado, não é mais ou menos isso que se poderia chamar de transgressão?"51 Poderíamos afirmar que a personagem Charlotte se despia e seduzia os homens num acesso de loucura. Pois bem, mas o acesso de loucura, para Nancy, nada mais é do que a única via de entrar no corpo, já que, em outras circunstâncias, os corpos são absolutamente invioláveis: "Cada uno es una virgen, una vestal en su lecho, y no es por estar cerrado que es virgen, sino por estar abierto. Es "lo abierto" lo que es virgen, y lo es para siempre. El abandono permanece sin acceso, la extensión, sin entrada." ${ }^{, 52}$

Como Maria Egipcíaca, Charlotte transita entre a violação (o acesso de loucura) e a inviolação, entre a abertura e o fechamento de seu corpo (e de sua alma). Mas o corpo é movimento, e grita, apela, goza, dói, debate-se com o pensamento. O pensamento é um corpo. E o corpo faz o mundo. Nancy expressa essa idéia com poesia:

Los cuerpos se cruzan, se rozan, se apretujan, se estrechan o se enfrentan tantas señas se hacen, tantas señales, apelaciones, advertencias, que ningún sentido definido puede saturar. Los cuerpos tienen sentido más-allá-delsentido. Son un exceso de sentido. Por eso un cuerpo parece cobrar sentido cuando está muerto, paralizado. [...] En realidad, el cuerpo no deja de moverse. [...] El cuerpo es lo movido del alma. ${ }^{53}$

\footnotetext{
${ }^{50}$ BATAILLE, Georges. O erotismo. Op. Cit. p. 125.

51 FOUCAULT, Michel. "Prefácio à transgressão". In.: Ditos \& escritos III. Estética: Literatura e pintura, música e cinema. 2 ed. Org. Manuele de Barros da Motta. Tradução de Inês Autran Dourado Barbosa. Rio de Janeiro: Forense Universitária, 2009. p. 29.

${ }^{52}$ NANCY, Jean-Luc. Corpus. Op. Cit. p. 46.

${ }^{53}$ NANCY, Jean-Luc. 58 indícios sobre el cuerpo, Extensión del alma. p. 20.
} 
E com Nancy podemos afirmar que a graça se penetra em mulheres como Charlotte, Ruth, Maria Egipcíaca - a partir de seus abandonos, onde o pecado as atravessa. Corpos expostos, em movimento. Todas elas libertas, tal como Maria Madalena, que "es pura en su cabellera impura, es santa en su pecado. No es más que la exposición del pecado a la gracia." 54

\section{REFERÊNCIAS}

BANDEIRA, Manuel. Estrela de Vida Inteira. 34a ed. Rio de Janeiro: José Olympio Editora, 1993, p. 106.

BATAILLE, Georges. O erotismo. Trad. Antonio Carlos Viana. Porto Alegre: L\&PM, 1987.

BLANCHOT, Maurice. O livro por vir. Tradução: Leyla Perrone-Moisés. São Paulo: Martins Fontes, 2005.

FOUCAULT, Michel. Ditos \& escritos III. Estética: Literatura e pintura, música e cinema. $2^{\mathrm{a}}$ ed. Org. Manoel Barros da Motta. Tradução de Inês Autran Dourado Barbosa. Rio de Janeiro: Forense Universitária, 2009.

LISPECTOR, Clarice. A via crucis do corpo. Rio de Janeiro: Nova Fronteira, 1984.

MEIRELES, Cecília. Oratório de Santa Maria Egipcíaca. Rio de Janeiro: Nova Fronteira, 1996.

NANCY, Jean-Luc . 58 indicios sobre el cuerpo, Extensión del alma. Traducido por Daniel Alvaro. Buenos Aires: Ediciones La Cebra, 2007.

. Corpus. Traducción de Patricio Bulnes. Madrid: Arena Libros, 2003.

. El "hay" de la relación sexual. Traducción: Cristina de Peretti y Francisco J. Vidarte. Madrid: Editorial Síntesis, 2001.

El peso de un pensamiento. Traducción de Joana Masó y Javier Bassas Vila.

El intruso. Traducción Margarita Martínez. Buenos Aires: Amorrortu, 2006.

. Las musas. Traducción de Horacio Pons. Buenos Aires: Amorrotu, 2008.

. Noli me tangere. Ensayo sobre el levantamiento del cuerpo. Traducción de María Tabuyo y Augustín López. Madrid: Editorial Trotta, 2006.

\footnotetext{
${ }^{54}$ NANCY, Jean-Luc. Noli me tangere. p. 94.
} 


\section{FILMOGRAFIA}

MEDOS PRIVADOS, LUGARES PÚBLICOS. Dir. Alain Resnais. França/Itália, 2006. 120 min. Color. 